\title{
TINGKAT PENGETAHUAN DAN SIKAP MASYARAKAT TENTANG PENYAKIT KECACINGAN BERPENGARUH TERHADAP KEJADIAN PENYAKIT KECACINGAN
}

\author{
Saidatina Hadijah, Abdul Khair, Noraida \\ Poltekkes Kemenkes Banjarmasin Jurusan Kesehatan Lingkungan \\ Jl. H. Mistar Cokrokusumo No.1A Banjarbaru Kalimantan Selatan 70714 \\ e-mail: saidatina_hadijah@yahoo.com
}

\begin{abstract}
The Level of Knowledge and Attitudes of The Public About Helminthiasis Effects With The Incidence of Helminthiasis. Worm disease is an infectious disease caused by parasites in the form of worms. The cause is soil-transmitted helminthiases (STH), which are intestinal worms that are transmitted to humans through soil contaminated by feces. STH infection can cause people to experience malnutrition. Severe infections can interfere with physical growth and cognitive development of sufferers. The purpose of this study was to determine the correlation between the level of knowledge and people's attitudes about helminthiasis with helminthiasis. This type of research was analytic with the research design using the case control method. The sample in this study was 38 respondents consisting of 19 people with helminthiasis and 19 did not suffer from helminthiasis. Data analysis using chi-square test. Chi-square test results showed the $p$ value for the correlation of the variable level of knowledge of $0,312>$ alpha $(0,05)$ and the correlation of the attitude variable of 0,501> alpha $(0,05)$ it can be stated that there is no relationship between the level of knowledge and attitudes of the community about the disease helminthiasis with the incidence of helminthiasis in the working area of cempaka puskesmas. If this research is to be continued, in order to be better, then the research sample should be expanded and other possible factors become one of the causes of STH infection such as clean and healthy life behavior, latrine quality, water quality, soil quality and others.
\end{abstract}

Keywords: Knowledge; attitude; helminthiasis

\begin{abstract}
Abstrak: Tingkat Pengetahuan dan Sikap Masyarakat Tentang Penyakit Kecacingan Berpengaruh Terhadap Kejadian Penyakit Kecacingan. Kecacingan disebabkan oleh parasit yaitu cacing merupakan penyakit infeksi. Penyebab kecacingan yaitu soil transmitted helminthiases (STH), merupakan cacing usus yang menular ke manusia yang terkontaminasi tinja melalui tanah. Masyarakat yang terinfeksi STH akan mengalami malnutrisi. Jika infeksi yang di derita berat maka pertumbuhan fisik dan perkembangan kognitif penderitanya akan terganggu. Tujuan dari penelitian ini untuk mengetahui hubungan antara tingkat pengetahuan dan sikap masyarakat tentang penyakit kecacingan dengan kejadian kecacingan. Jenis penelitian ini bersifat analitik dengan desain penelitian menggunakan metode kasus kontrol (case control). Sampel pada penelitian ini sebanyak 38 responden yang terdiri dari 19 penderita kecacingan dan 19 tidak menderita kecacingan. Analisis data menggunakan uji chi-square. Hasil uji chisquare menunjukkan nilai p-value untuk hubungan variabel tingkat pengetahuan sebesar 0,737 > alpha $(0,05)$ dan hubungan variabel sikap sebesar 0,737 > alpha $(0,05)$ dapat dinyatakan bahwa tidak ada hubungan tingkat pengetahuan dan sikap masyarakat tentang penyakit kecacingan dengan kejadian kecacingan di wilayah kerja Puskesmas Cempaka. Penelitian selanjutnya agar lebih baik maka sampel penelitian sebaiknya lebih diperbanyak dan faktor-faktor lain yang memungkinkan menjadi salah satu penyebab penyebaran infeksi STH seperti perilaku hidup bersih dan sehat, kualitas jamban, kualitas air, kualitas tanah dan lain-lain.
\end{abstract}

Kata Kunci: Pengetahuan; sikap; kecacingan 


\section{PENDAHULUAN}

Kecacingan disebabkan oleh parasit yaitu cacing merupakan penyakit infeksi. Penyebab kecacingan yaitu soiltransmitted helminthiases (STH), merupakan cacing usus yang menular ke manusia yang terkontaminasi tinja dari tanah. Masyarakat yang terinfeksi STH akan mengalami malnutrisi. Jika infeksi yang di derita berat maka pertumbuhan fisik dan perkembangan kognitif penderitanya akan terganggu. Masyarakat akan mengalami penurunan dalam memproses informasi baru dan kemampuan belajar apabila sudah lama terinfeksi STH, hal itu menjadi penyebab seseorang sulit mengembangkan daya pikirnya[1].

Untuk wilayah Indonesia prevalensi kecacingan tahun 2012 berada pada angka diatas 20 persen dengan prevalensi paling tinggi mencapai 76,67 persen, infeksi kecacingan mulai menurun pada tahun 2011 dilakukan survei di seluruh Provinsi. Prevalensi di Nusa Tenggara Barat 92 persen, Jawa barat 90 persen, Kalimantan 79 persen, Sumatera 78 persen, dan Sulawesi 8 persen[2].

Dari data yang di dapatkan dari Dinas Kesehatan Kota Banjarbaru Tahun 2019 untuk penyakit kecacingan dari 9 Puskesmas yang ada di Kota Banjarbaru tercatat jumlah penderita kecacingan di Puskesmas Cempaka sebesar 19 orang penderita dari jumlah penduduk 32.706 jiwa.

Penambangan intan di Kecamatan Cempaka Banjarbaru merupakan penambangan tradisional dengan menggunakan sistem dumping atau cara penambangan dengan cara mengupas tanah permukaan lalu kemudian dilanjutkan dengan penggalian secara manual tanpa menggunakan mesin. Sistem kerja tradisional ini membuat pekerja harus bersentuhan langsung dengan tanah sepanjang hari, hal inilah yang menjadi risiko pekerja terinfeksi kecacingan[3].

Hal yang paling penting untuk membentuk tindakan seseorang adalah pengetahuan. Untuk mengurangi resiko terkena penyakit maka seseorang harus mamiliki perilaku atau tindakan yang baik. Status kecacingan berpengaruh terhadap pengetahuan dan berperan sangat penting dalam mencegah penyakit kecacingan, oleh karena itu resiko seseorang terinfeksi cacing akan meningkat apabila memiliki pengetahuan yang rendah[1].

Dari penjelasan yang sudah diuraikan, jika masyarakat memiliki tingkat pengetahuan dan sikap yang baik terhadap penyakit kecacingan maka resiko terinfeksi kecacingan dapat dicegah. Untuk itu, menarik untuk dilakukan penelitian mengenai mengetahui hubungan antara tingkat pengetahuan dan sikap masyarakat tentang penyakit kecacingan pada masyarakat Kecamatan Cempaka.

\section{BAHAN DAN CARA PENELITIAN}

Jenis penelitian ini bersifat analitik yaitu dengan menghubungkan pengetahuan dan sikap masyarakat tentang penyakit kecacingan dengan kejadian kecacingan. Desain pada penelitian ini menggunakan metode kasus kontrol (case control) menggunakan pendekatan retrospektif, yaitu dengan membandingkan antara kelompok kasus dengan kelompok kontrol[4].

Metode pengumpulan data pada penelitian ini dengan wawancara menggunakan kuesioner untuk mendapatkan data responden. Data yang diperoleh diolah dan disajikan dalam bentuk tabel distribusi frekuensi untuk mengetahui hubungan tingkat pengetahuan dan sikap masyarakat tentang penyakit kecacingan dengan kejadian kecacingan, dianalisis dengan menggunakan perhitungan statistik yaitu dengan Chi-Square.

\section{HASIL DAN PEMBAHASAN}

Hasil data distribusi tingkat
pengetahuan dan sikap masyarakat
tentang penyakit kecacingan dengan
kejadian kecacingan.
Tingkat Pengetahuan Masyarakat
Tentang Penyakit Kecacingan


Tabel 1. Distribusi Frekuensi Responden Berdasarkan Tingkat Pengetahuan Masyarakat Tentang Penyakit Kecacingan

\begin{tabular}{ccccc}
\hline \multirow{2}{*}{ No. } & \multirow{2}{*}{ Tingkat Pengetahuan } & \multicolumn{2}{c}{ Frekuensi } \\
& & Jumlah & $\%$ \\
\hline 1. & Kurang & & 14 & 36,8 \\
2. & Baik & \multirow{2}{*}{ Total } & 24 & 63,2 \\
& & & 38 & 100 \\
\hline
\end{tabular}

Berdasarkan Tabel dapat diketahui bahwa tingkat pengetahuan masyarakat tentang penyakit kecacingan paling banyak yaitu pada kategori Baik sebanyak 24 responden $(63,2 \%)$.

Berdasarkan penelitian masyarakat di wilayah kerja Puskesmas cempaka paling banyak memiliki tingkat pendidikan SD dan SMP ini membuktikan bahwa masyarakat di wilayah kerja Puskesmas Cempaka sudah memiliki pendidikan yang dasar maka memungkinkan masyarakatnya untuk memiliki tingkat pengetahuan yang baik.

Ada beberapa faktor yang berpengaruh pada tingkat pengetahuan faktor tersebut adalah faktor eksternal dan faktor internal. faktor eksternal terdiri dari informasi, sosial budaya dan lingkungan.

Masyarakat yang memiliki pengetahuan tentang suatu hal tidak hanya melalui jenjang pendidikan saja, tetapi juga di tambahkan dari terpapar informasi sedangkan Faktor internal terdiri dari pendidikan, motivasi dan persepsi[5].

Teori tersebut sesuai dengan hasil dari wawancara yang dilakukan peneliti dengan masyarakat yang menjelaskan jika informasi yang mereka terima lebih banyak didapatkan dari petugas kesehatan dari puskesmas dan dari media cetak ataupun elektronik.

Sikap Masyarakat Tentang Penyakit Kecacingan

Tabel 2. Distribusi Frekuensi Responden Berdasarkan Sikap Masyarakat Tentang Penyakit Kecacingan

\begin{tabular}{clcc}
\hline \multirow{2}{*}{ No. } & \multirow{2}{*}{ Sikap Masyarakat } & Jumlah & Frekuensi \\
$\%$
\end{tabular}

Berdasarkan Tabel dapat diketahui bahwa sifat responden tentang panyakit kecacingan paling banyak ada pada kategori positif yaitu sebanyak 24 responden $(63,2 \%)$. Pengalaman pribadi, kebudayaan, orang lain yang dianggap penting, media massa, institusi atau lembaga pendidikan dan lembaga agama, faktor emosi dalam diri individu merupakan bebrapa faktor yang berpegaruh dalam pembentukan sebuah sikap[6]. Oleh karena itu semakin tinggi jenjang pendidikan seseorang maka akan semakin matang sikap yang dimilikinya karena dipengaruhi oleh ajaran dari lembaga pendidikan.

Dari hasil wawancara yang dilakukan peneliti dengan responden pada saat penelitian, faktor yang sangat berpengaruh pada sikap responden dalam penelitian ini adalah pengalaman pribadi responden yang pernah menderita kecacingan. Dari pengalaman itu menjadikan responden bersikap positif agar terhindar dari penyakit kecacingan.

Tingkat Pengetahuan dan Kejadian Kecacingan 
Tabel 3. Tabel Silang Tingkat Pengetahuan Masyarakat dengan Kejadian Kecacingan

\begin{tabular}{|c|c|c|c|c|c|c|}
\hline \multirow{3}{*}{ No } & \multirow{3}{*}{ Tingkat Pengetahuan } & \multicolumn{4}{|c|}{ Kejadian Kecacingan } & \multirow{3}{*}{ Jumlah } \\
\hline & & \multicolumn{2}{|c|}{$\begin{array}{c}\text { Kecacingan } \\
\text { (Kasus) }\end{array}$} & \multicolumn{2}{|c|}{$\begin{array}{c}\text { Tidak } \\
\text { Kecacingan } \\
\text { (Kontrol) }\end{array}$} & \\
\hline & & $\mathrm{n}$ & $\%$ & $\mathrm{n}$ & $\%$ & \\
\hline 1. & Kurang & 8 & 42,1 & 6 & 31,6 & 14 \\
\hline \multirow[t]{3}{*}{2.} & Baik & 11 & 57,9 & 13 & 68,4 & 24 \\
\hline & Total & 19 & 100 & 19 & 100 & 38 \\
\hline & $\mathrm{P}=0,737$ & & & & $\alpha=($ & \\
\hline
\end{tabular}

Hasil analisis data dengan menggunakan uji chi-square diperoleh nilai pvalue sebesar $0,737>$ alpha $(0,05)$ maka Ho diterima sehingga dapat di-katakan bahwa tidak ada hubungan anta-ra tingkat pengetahuan masyarakat ten-tang penyakit kecacingan dengan kejadian kecacingan di wilayah kerja Puskesmas Cempaka.
Hasil penelitian ini tidak berhubungan disebabkan oleh sudah baiknya tingkat pengetahuan masyarakat yang ada di Wilayah kerja puskesmas Cempaka baik itu karena tingkat pendi-dikan yang sudah mendasar dan dari infomasiinformasi yang diperoleh mela-lui media lain.

\section{Sikap Masyarakat dan Kejadian Kecacingan}

Tabel 4. Tabel Silang Sikap Masyarakat dengan Kejadian Kecacingan

\begin{tabular}{|c|c|c|c|c|c|c|}
\hline \multirow{3}{*}{ No. } & \multicolumn{6}{|c|}{ Kejadian Kecacingan } \\
\hline & \multirow[t]{2}{*}{ Sikap Masyarakat } & \multicolumn{2}{|c|}{$\begin{array}{c}\text { Kecacingan } \\
\text { (Kasus) }\end{array}$} & \multicolumn{2}{|c|}{$\begin{array}{c}\text { Tidak } \\
\text { Kecacingan } \\
\text { (Kontrol) }\end{array}$} & \multirow[t]{2}{*}{ Jumlah } \\
\hline & & $\mathrm{n}$ & $\%$ & $\mathrm{~N}$ & $\%$ & \\
\hline 1. & Negatif & 6 & 31,6 & 8 & 42,1 & 14 \\
\hline \multirow[t]{3}{*}{2.} & Positif & 13 & 68,4 & 11 & 57,9 & 24 \\
\hline & Total & 19 & 100 & 19 & 100 & 38 \\
\hline & $\mathrm{p}=0,737$ & & & \multicolumn{3}{|c|}{$\alpha=0,05$} \\
\hline
\end{tabular}

Hasil analisis data dengan menggunakan uji chi-square diperoleh nilai p-value sebesar $0,737>$ alpha $(0,05)$ maka Ho diterima sehingga dapat dikatakan bahwa tidak ada hubungan antara sikap masyarakat tentang penyakit kecacingan dengan kejadian kecacingan di wilayah kerja Puskesmas Cempaka.

Sikap adalah respon seseorang yang tertutup terhadap objek tertentu atau stimulus. Pengetahuan adalah faktor yang sangat berperan penting dalam menentukan sikap. Sikap merupakan keinginan untuk bertindak. Tindakan atau aktifitas belum merupakan fungsi dari sikap[5]. Oleh sebab itu, tindakan yang nyata dari seseorang belum tentu mempunyai sikap yang baik. Itu memungkinkan menjadi penyebab tidak ditemu- kan adanya hubungan antara sikap masyarakat tentang penyakit kecacingan dengan kejadian kecacingan.

\section{KESIMPULAN DAN SARAN}

Dari penelitian yang sudah dilaksanakan di wilayah kerja Puskesmas Cempaka maka dapat disimpulkan bahwa Tidak terbukti secara statistik hubungan antara tingkat pengetahuan tentang penyakit kecacingan dengan kejadian kecacingan dan tidak terbukti secara statistik hubungan antara sikap masyarakat tentang penyakit kecacingan dengan kejadian kecacingan. Untuk saran apabila penelitian ini teruskan, untuk lebih baik maka sampel penelitian agar lebih diperbanyak dan faktor- faktor lain yang memungkinkan menjadi salah satu 
penyebab penyebaran infeksi STH seperti pelaksanaan atau praktik mencegah kecacingan dalam kehidupan sehari- hari, perilaku hidup bersih dan sehat, kualitas jamban, kualitas air, kualitas tanah dan lain-lain.

\section{KEPUSTAKAAN}

1. Lestari TW. Hubungan Tingkat Pengetahuan, Sikap Dan Perilaku Pencegahan Kecacingan Dengan Status Kecacingan Siswa Sdn 03 Pontianak Timur Kotamadya Pontianak Tahun 2014. J Mhs PSPD FK Univ Tanjungpura. 2014;(Vol 1, No 1 (2014): Jurnal Mahasiswa PSPD FK UNTAN Tahun 2014).

2. Tambak R. Pengaruh Penyuluhan Kesehatan Menggunakan Media Video Tentang Kecacingan Terhadap Pengetahuan Dan Sikap Siswa Sdn 122375 Pematangsiantar Tahun 2017.
Skripsi Fak Kesehat Masy Univ Sumatera Utara Medan 2018. 2018;

3. Sari W, Giri R. Hubungan kejadian infeksi cacing tambang dengan anemia pada pekerja tambang intan tradisional Kelurahan Sungai Tiung Kecamatan Cempaka Kota Banjarbaru tahun 2014 The relationship of hookworm infection and anemia on the traditional diamond mine workers in Sungai Tiung Village of Cempaka Sub-District Banjarbaru City 2014. 2016;(1):27-31.

4. Notoatmodjo S. Promosi Kesehatan dan Perilaku Kesehatan. Jakarta: PT. Rineka Cipta; 2012.

5. Notoatmodjo S. Promosi Kesehatan dan Ilmu Perilaku. Jakarta: Rineka Cipta; 2007.

6. Azwar. Sikap Manusia Teori dan Pengukurannya. Edisi 2. Yogyakarta: Pustaka Belajar; 2013. 
